Brazilian Journal

of Chemical

ISSN 0104-6632

Engineering

\title{
MATHEMATICAL MODELING OF THE ELECTRIC CURRENT GENERATION IN A MICROBIAL FUEL CELL INOCULATED WITH MARINE SEDIMENT
}

\author{
J. T. Teleken ${ }^{1}$, J. de Sá Silva ${ }^{2}$ M. F. Fraga ${ }^{3}$, C. S. Ogrodowski², \\ F. B. Santana ${ }^{2}$ and B. A. M. Carciofi ${ }^{1 *}$ \\ ${ }^{1}$ Department of Chemical and Food Engineering, Federal University of Santa Catarina, (UFSC), \\ Campus João David Ferreira Lima, Trindade, CEP: 88040-900, Florianópolis - SC, Brazil. \\ Phone + 5548 37216408; Fax: + 554837219687 \\ *E-mail: bruno.carciofi@ufsc.br \\ ${ }^{2}$ School of Chemistry and Food, Federal University of Rio Grande, (FURG), Campus Carreiros, \\ Avenida Itália, km 08, PO Box 474, CEP: 96.201-900, Rio Grande - RS, Brazil. \\ ${ }^{3}$ State Power Generation and Transmission Company, (CEEE-GT), Av. Joaquim Porto Villanova 201, \\ CEP: 91410-400, Porto Alegre - RS, Brazil.
}

(Submitted: April 1, 2015 ; Revised: September 3, 2015 ; Accepted: October 5, 2015)

\begin{abstract}
Microbial fuel cells (MFC) are electrochemical devices that utilize the ability of some microorganisms to oxidize organic matter and transfer electrons resulting from their metabolism to an insoluble acceptor. The goal of the present study was to model the kinetics of electrical current generation from an MFC inoculated with marine sediment. For this purpose, a differential equation system was used, including the Nernst-Monod relationship and Ohm's Law, to describe the microbial metabolism and the mechanism of extracellular electron transfer (EET), respectively. The experimental data obtained by cyclic voltammetry analysis were properly described by the model. It was concluded that marine microorganisms preferably use a direct mechanism of EET by means of nanowires to establish the electrochemical contact with the anode. The mathematical modeling could help understand MFC operation and, consequently, contribute to improving power generation from this source.

Keywords: Waste treatment; Biofilm; Nanowires; Effluent; Green energy.
\end{abstract}

\section{INTRODUCTION}

A wide variety of microorganisms have the ability to reduce insoluble compounds such as metal oxides as a part of their strategy to obtain energy. This ability has received considerable attention due to the possibility of generating electric energy from organic matter in microbial fuel cells (MFC) (Lovley, 2012). A MFC can utilize complex organic substrates, including domestic, industrial, and agricultural wastewater, as a source to produce power, drawing attention as a promising technology connecting sustainable energy and waste treatment (Pant et al., 2010; ElMekawy et al., 2015).

A classical MFC design includes two compartments, an anaerobic anodic chamber and an aerobic cathode chamber, separated by a cation exchange membrane. In this system, electricity is generated when microorganisms transfer electrons from the oxidation reaction of organic matter to an electrode (anode) connected to an electrical circuit. From the anode, electrons are conducted through the circuit to a second electrode (cathode), separated from the first by the cation exchange membrane, where they com-

*To whom correspondence should be addressed 
bine with protons and with the final acceptor in a reduction reaction. Thus, a positive and a negative charge density are present at the cathode and at the anode, respectively, resulting in a potential difference for electron transport in the circuit and leading to power generation (Logan and Regan, 2006, Oliveira et al., 2013a; Venkata Mohan et al., 2014; ElMekawy et al. 2015).

Exoelectrogenic microorganisms are naturally found in anaerobic environments such as aquatic sediments (Tender et al., 2002; Holmes et al., 2004), soils (Niessen et al., 2006; Futamata et al., 2013), and sludge from waste treatment plants (Kim et al., 2004). Preferably, they develop adhered to the surface of the electrodes in the form of biofilms and are able to use diverse anaerobic metabolic pathways to oxidize the carbon sources (Venkata Mohan et al., 2014).

This microbial class establish as electrochemical contact with such electrodes using three distinct mechanisms of extracellular electron transfer (EET): 1) direct contact between the proteins present in the cell membrane (cytochromes) and the anode (Bond and Lovley, 2003); 2) diffusion of self-produced electron carriers, such as flavins or some artificial redox mediators, between cells and the anode (Rabaey et al., 2004; Marsili et al., 2008a); and 3) conduction of electrons through solid components such as the extracellular materials (nanowires) and the multiple bacterial layers that comprise the biofilm (Reguera et al., 2006; Gorby et al., 2006). Biofilms with mixed culture can present more than one of these EET, whereas a pure biofilm tends to be limited (Venkata Mohan et al., 2014; Sharma et al., 2014).

Therefore, to model the kinetics of electrical current generation in a MFC, one should consider the intracellular overpotential, associated with the biological reaction, and the extracellular overpotentials, associated with the EET mechanism and the transport of substrate and metabolites within the biofilm. Microbial kinetics in biological reactors are often modeled by the Monod relationship (Rittmann and McCarty, 2001); however, this model cannot be used in its original form to describe the current generation kinetics in an MFC. Thus, according to the EET mechanism employed by the biofilm, different behaviors are expected. Systematically, the models available in the literature state that the biological reaction can be described by a dual limitation relationship, which involves the substrate concentration and the contraction or the electric potential of the EET mechanism (Picioreanu et al., 2007, Marcus et al., 2007, Pinto et al., 2010; Oliveira et al., 2013b). The EET is modeled according to the mechanism used by the exoelectrogenic bacteria: If the transport is done by mediators, it can be modeled by applying Fick's law (Picioreanu et al., 2007, 2010) or, if transport is by conduction through the solid components of the biofilm, it can be modeled by applying Ohm's law (Marcus et al., 2007). The reactions occurring between the EET mechanism and the electrode are described by electrochemical models, such as the Butller-Volmer relationship (Picioreanu et al., 2007, 2010; Zeng et al., 2010).

In light of the above, the objective of this study was to identify the main EET mechanism and mathematically model the electric current generation kinetics as a function of the electrical potential of the anode of a dual-chamber MFC inoculated with sediment of marine origin.

\section{MATERIALS AND METHODS}

\section{Inoculum and Culture Medium}

Sediment of marine origin, collected on the southern coast of Brazil (Rio Grande, RS, Brazil), was used as inoculum for the MFC. The culture medium used was composed of $\mathrm{NaHCO}_{3}\left(2.5 \mathrm{~g} \mathrm{~L}^{-1}\right), \mathrm{CaCl}_{2} \cdot 2 \mathrm{H}_{2} \mathrm{O}$ $\left(0.1 \mathrm{~g} \mathrm{~L}^{-1}\right), \mathrm{KCl}\left(0.1 \mathrm{~g} \mathrm{~L}^{-1}\right), \mathrm{NH}_{4} \mathrm{Cl}\left(1.5 \mathrm{~g} \mathrm{~L}^{-1}\right) \mathrm{NaH}_{2} \mathrm{PO}_{4}$ $\mathrm{H}_{2} \mathrm{O}\left(0.6 \mathrm{~g} \mathrm{~L}^{-1}\right) \mathrm{Na}_{2} \mathrm{HPO}_{4} \cdot 12 \mathrm{H}_{2} \mathrm{O}\left(1.87 \mathrm{~g} \mathrm{~L}^{-1}\right), \mathrm{NaCl}$ $\left(0.1 \mathrm{~g} \mathrm{~L}^{-1}\right), \mathrm{MgCl}_{2} \cdot 6 \mathrm{H}_{2} \mathrm{O}\left(0.1 \mathrm{~g} \mathrm{~L}^{-1}\right), \mathrm{MgSO}_{4} 7 \mathrm{H}_{2} \mathrm{O}$ $\left(0.1 \mathrm{~g} \mathrm{~L}^{-1}\right), \mathrm{MnCl}_{2} \cdot 4 \mathrm{H}_{2} \mathrm{O}\left(0.005 \mathrm{~g} \mathrm{~L}^{-1}\right) \mathrm{NaMoO}_{4} 2 \mathrm{H}_{2} \mathrm{O}$ $\left(0.001 \mathrm{~g} \mathrm{~L}^{-1}\right)$, and yeast extract $\left(0.05 \mathrm{~g} \mathrm{~L}^{-1}\right)$. Acetate ion $\left(\mathrm{CH}_{3} \mathrm{COO}^{-}\right)$was used as carbon source (electron donor) at concentrations of $5 \mathrm{~g} \mathrm{~L}^{-1}$ and $10 \mathrm{~g} \mathrm{~L}^{-1}$ of COD. Initially, the MFC was inoculated with the suspension obtained by mixing marine sediment (at $5 \mathrm{~g} \mathrm{~L}^{-1}$ of COD) with the culture medium at a 2:1 (w/w) ratio.

\section{Microbial Fuel Cell}

The experiments were performed in a dual-chamber acrylic MFC with a total volume of $2.5 \mathrm{~L}, 60 \%$ destined for the anodic chamber $(1.5 \mathrm{~L})$ and $40 \%$ dedicated to the cathodic chamber $(1 \mathrm{~L})$. A cation exchange membrane (Membranes International Inc., CMI-7000S, USA) was used to separate both chambers. Graphite plates with a surface area of $115 \mathrm{~cm}^{2}$ each were used as electrodes. In the anodic chamber, the two graphite plates were placed at 5 and $10 \mathrm{~cm}$ from the membrane, while, in the cathodic chamber, the plate was placed at $5 \mathrm{~cm}$ from the membrane. Figure 1 illustrates the MFC configuration. An external resistor $\left(R_{\text {ext }}\right)$ of $1 \mathrm{k} \Omega$ connected both anodic electrodes to the cathodic electrode. The anodic chamber was kept under constant agitation by an impeller at $300 \mathrm{rpm}$. In the cathodic chamber, a $50 \mathrm{mM}$ potassium 
ferricyanide $\left(\mathrm{K}_{3} \mathrm{Fe}(\mathrm{CN})_{6}\right)$ solution was used as the final electron acceptor. The MFC was stored in a thermostat-controlled chamber (Eletrolab, model EL101/2, Brazil) to keep the operation temperature constant at $35^{\circ} \mathrm{C}$ over the 280 days of the experiment.
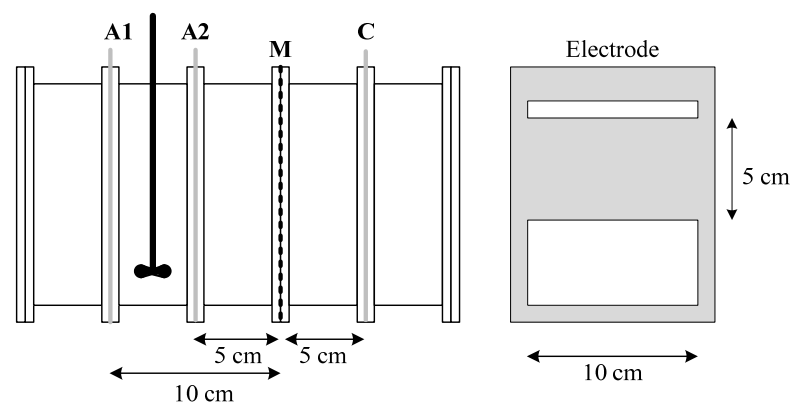

Figure 1: Schematics of the MFC and the electrode geometry. A1 and A2 are the anodes, $\mathrm{C}$ the cathode and $\mathrm{M}$ the cation exchange membrane.

\section{Operating Conditions}

The anodic chamber was operated in batch mode during the first two days of the experiment (startup period). Next, operational cycles alternatingly composed of sequential batch and continuous regimes were initiated. From the 37th day onwards, the acetate concentration in the feed solution increased from $5 \mathrm{~g} \mathrm{~L}^{-1}$ to $10 \mathrm{~g} \mathrm{~L}^{-1}$ of COD.

The sequential batch regime was carried out daily by renewing the anodic medium (24-hour feeding cycles), according to the procedures described below: 1) renewal of $0.3 \mathrm{~L}$ of the culture medium containing $75 \%$ of solids present in the effluent removed from the anodic chamber $(0.2 \mathrm{~h})$; 2) Bio-electrochemical conversion of acetate in electric current $(23 \mathrm{~h})$; 3) removing the effluent from the anodic chamber $(0.2 \mathrm{~h})$; 4) separation of suspended solids in the effluent $(0.6 \mathrm{~h})$. The last step was performed in a centrifuge (Hitachi, model CR22 GIII, Japan), with the rotation set at $18,800 \mathrm{~g}$. Approximately $75 \%$ of the solids obtained by centrifugation were suspended in the feed solution and returned to the system, reestablishing the volume of liquid in the reactor (step 1). During the culture medium renewal procedure, agitation in the chamber was temporarily interrupted.

The continuous mode without cell recycle was implemented by maintaining a constant flow rate of the culture medium for $24 \mathrm{~h}$. The operations were performed with different feeding flows with the purpose of evaluating the effect of the material solubilized in the anodic chamber on electric current generation. Eight operations were performed: on day 25 and feed flow of $2.70 \mathrm{~L} \mathrm{~d}^{-1}$ (CON1), day 129 and
$2.50 \mathrm{~L} \mathrm{~d}^{-1}$ (CON2), day 149 and $1.77 \mathrm{~L} \mathrm{~d}^{-1}(\mathrm{CON} 3)$, day 170 and $2.77 \mathrm{~L} \mathrm{~d}^{-1}$ (CON4), day 191 and $2.50 \mathrm{~L} \mathrm{~d}^{-1}$ (CON5), day 212 and $4.60 \mathrm{~L} \mathrm{~d}^{-1}$ (CON6), day 246 and $9.66 \mathrm{~L} \mathrm{~d}^{-1}$ (CON7), and day 268 and $17.43 \mathrm{~L} \mathrm{~d}^{-1}$ (CON8).

The cathodic chamber was operated in batch mode. The solution of potassium ferricyanide was periodically replaced every 12 days on average, totaling 23 renewals of the solution.

\section{Electrochemical Monitoring}

The voltage developed between the anode and the cathode $\left(V_{c e l}\right)$, was measured with a digital multimeter (Icel, MD6680, Brazil) and a software (Icel, UT803 version 1.00, Brazil) was used for data acquisition and recording on a computer terminal every $60 \mathrm{~s}$. The current density $j\left(\mathrm{~A} \mathrm{~m}^{-2}\right)$ was determined from Equation (1), by measuring the $V_{c e l}$ of the electrical circuit with external resistance $R_{\text {ext }}(\Omega)$.

$$
j=\frac{1}{A_{\text {anode }}}\left(\frac{V_{\text {cel }}}{R_{\text {ext }}}\right)
$$

in which $A_{\text {anode }}$ is the total area of the anodes $(0.023$ $\mathrm{m}^{2}$ ).

\section{Cyclic Voltammetry - Biofilm}

Cyclic voltammetry scans (CV), used to model the current generation kinetics in the MFC, were conducted after day 160 of reactor operation, ensuring the full development of the biofilm on the anode. These were always carried out after the feed steps to minimize the effects of substrate limitation. After feeding ( $10 \mathrm{~g} \mathrm{~L}^{-1}$ of COD, $20 \%$ of the volume of the anodic chamber) the initial acetate concentration in the chamber was approximately $32.3 \mathrm{mM}$. When the acetate ion concentration is greater than $5 \mathrm{mM}$ in reactors with Geobacter sulfurreducens biofilm formation, additional acetate has no effect on the current generation rate (LaBelle and Bond, 2010). On the other hand, it was also observed that the electric current generated by a Geobacter sulfurreducens biofilm was affected only at acetate concentrations below $3 \mathrm{mM}$ (Marsili et al., 2008b).

$\mathrm{CV}$ analyses were performed using a potentiostat (Metrohm, PGSTAT 101, Switzerland), the reference electrode of $\mathrm{Ag} / \mathrm{AgCl} 3 \mathrm{M} \mathrm{KCl}$ (Metrohm, 6.0726.100, Switzerland), the anode at $5 \mathrm{~cm}$ from the membrane as working electrode, and the cathode as a counter electrode. The selected parameters to carry out the technique were: $\mathrm{E}_{\text {initial }}=-0.6 \mathrm{~V}(v \mathrm{Ag} / \mathrm{AgCl})$, 
$\mathrm{E}_{\text {final }}=0.0 \mathrm{~V}(v s \mathrm{Ag} / \mathrm{AgCl})$, equilibrium time of $5 \mathrm{~s}$, scan rates of $0.2,1,2.5,5$, and $10 \mathrm{mV} \mathrm{s}^{-1}$, and $3 \mathrm{cy}-$ cles. The interval from -0.6 to $0.0 \mathrm{~V}$ vs $\mathrm{Ag} / \mathrm{AgCl}$ (in relation to the standard hydrogen electrode: -0.378 to $0.222 \mathrm{~V} v s \mathrm{EPH}$ ) was selected in order to avoid injuries to cells derived from the high-potential reduction or oxidation and at the same time ensure the evaluation of the oxidation process of interest. This working range is similar to that used in studies with some of the microorganisms of Geobacter and Shewanella species (-0.558 to $0.242 \mathrm{~V}$ vs EPH) (Marsili et al., 2008a, 2008b, 2010). The low scan rates were selected with the aim of reducing the effects of capacitive current in the analysis response and reveal the biofilm's catalytic behavior (Harnisch and Freguia, 2012). In total, eight sets of $\mathrm{CV}$ analysis (different rates) were performed on days 161, 182, 195, 206, $220,226,256$, and 276 of operation.

\section{Cyclic Voltammetry - Anodic Effluent}

The cyclic voltammetry analyses of the effluent from the anode chamber were performed to investigate the importance of soluble compounds in current generation. While operating on a continuous basis, effluent samples of $40 \mathrm{ml}$ were collected at $0,3,6,9$, $12,15,18$, and $21 \mathrm{~h}$ after the start of operation. The samples were then transferred to a second electrochemical cell to proceed with the $\mathrm{CV}$ analysis. A glassy carbon electrode (Metrohm, OD =6 mm, ID = $1.6 \mathrm{~mm}$, QA017, Switzerland) was used as a working electrode, and a platinum electrode (Metrohm, 6.0331.000, Switzerland) as counter electrode. The technique's parameters were the same used in CV analysis of the biofilm.

\section{Scanning Electron Microscopy}

Scanning electron microscopy was used to qualitatively analyze the exoelectrogenic biofilm attached to the anode. Samples were collected from the anode electrodes and analyzed in a Zeiss scanning electron microscope, model DMS-940, at the end of reactor operation (day 280). The samples were fixated with a solution of glutaraldehyde $(6 \%)$, paraformaldehyde $(6 \%)$, and $0.1 \mathrm{M}$ cacodylate at a ratio of $1: 1: 1$. Subsequently, samples were dehydrated and ethanol was replaced with $\mathrm{CO}_{2}$.

\section{Mathematical Modeling of the Electric Current Generation Kinetics}

The mathematical model used to describe the electric current generation kinetics was based on the model proposed by Marcus et al. (2007). This model is for exoelectrogenic biofilms that predominantly use a direct mechanism of extracellular electron transfer. The biofilm model assumes a matrix conductor, in which the rate of substrate consumption is limited by the local concentration of the electron donor (ED) and the local electrical potential within the biofilm. The expression that describes the rate of substrate consumption written as the flow of substrate into the biofilm is known as the Nernst-Monod model, and is represented by Equation (2).

$$
\begin{gathered}
J_{E D}(z)=q_{\max } \rho_{f} f_{a} L_{f}\left[\frac{S_{E D}(z)}{S_{E D}(z)+K_{E D}}\right] \\
\left\{\frac{1}{1+\exp \left[-\frac{F}{R T} \eta(z)\right]}\right\}
\end{gathered}
$$

in which, $J_{E D}(z)$ is the mass flow of ED at a given spatial location within the biofilm $\left(\mathrm{g} \mathrm{m}^{-2} \mathrm{~s}^{-1}\right), q_{\max }$ is the maximum specific rate of ED consumption $\left(\mathrm{g} \mathrm{g}^{-1}\right.$ $\left.\mathrm{s}^{-1}\right), \rho_{f}$ is the specific biofilm mass $\left(\mathrm{g} \mathrm{m}^{-3}\right), f_{a}$ is the volume fraction of active biomass, $L_{f}$ is the biofilm thickness $(\mathrm{m}), \eta(z)=E_{\text {bio }}(z)-E_{K A}, E_{b i o}(z)$ is the electric potential at a given spatial position in the biofilm (V), $E_{K A}$ is the biofilm's electric potential (V) for $J_{E D}(z)=0.5 q_{\max } \rho_{f} f_{a} L_{f}, S_{E D}(z)$ is the mass concentration of ED $\left(\mathrm{g} \mathrm{m}^{-3}\right)$ in a given spatial location of the biofilm, $K_{E D}$ is the mass concentration of ED $\left(\mathrm{g} \mathrm{m}^{-3}\right)$ so that $J_{E D}(z)=0.5 q_{\max } \rho_{f} f_{a} L_{f}$, $F$ is the Faraday constant $\left(\mathrm{C} \mathrm{mol}^{-1}\right), R$ is the universal gas constant $\left(\mathrm{J} \mathrm{mol}^{-1} \mathrm{~K}^{-1}\right)$, and $T$ is the system temperature $(\mathrm{K})$.

All CV analyses of the biofilm were performed on the excess of the substrate, thus, the term referring to the limitation of $\mathrm{ED},\left[\frac{S_{E D}(z)}{S_{E D}(z)+K_{E D}}\right]$, in Equation (2) is approximated to the unit, and effects caused by the limited mass transport were not considered in the modeling. Ohm's law was used to describe the effects caused by the flow of electrons in the biofilm; it is represented by Equation (3) for a one-dimensional system.

$j(z)=-k_{\text {bio }} \frac{d \eta(z)}{d z}$

in which, $k_{b i o}$ is the biofilm conductivity $\left(\mathrm{S} \mathrm{m}^{-1}\right)$. 
The spatial charge distribution is described by the differential balance according to Equation (4):

$$
\frac{d j(z)}{d z}+F \gamma_{s} f e^{0} q_{\max } \rho_{f} f_{a}\left\{\frac{1}{1+\exp \left[-\frac{F}{R T} \eta(z)\right]}\right\}=0
$$

in which $\gamma_{s}$ is the total number of moles of electrons that can be oxidized per gram of substrate $\left(\mathrm{mol} \mathrm{g}^{-1}\right)$ and $f e^{0}$ is the Coulomb efficiency that expresses the fraction of the load transferred to the electrode versus the total amount available on the electron donor.

By combining Equations (3) and (4), and substituting $F \gamma_{s} f e^{0} q_{\max } \rho_{f} f_{a}=j_{\max } / L_{f}$, the expression that describes the electrical potential gradient within the biofilm was obtained, i.e., Equation (5):

$k_{b i o} \frac{d^{2} \eta(z)}{d z^{2}}-\frac{j_{\max }}{L_{f}}\left\{\frac{1}{1+\exp \left[-\frac{F}{R T} \eta(z)\right]}\right\}=0$

in which $j_{\max }$ is the specific maximum current density generated by the biofilm $\left(\mathrm{A} \mathrm{m}^{-2}\right)$.

The only solution of Equation (5) requires two boundary conditions: the electric potential being constant at the anode/biofilm interface (Equation (6)) and the absence of electronic flow in the biofilm/solution interface (Equation (7)):

$z=0, \quad \eta=V_{\text {anode }}$

$z=L_{f}, \quad k_{b i o} \frac{d \eta}{d z}=0$

in which $V_{\text {anode }}$ is defined in relation to $E_{K A}$, $V_{\text {anode }}=E_{\text {anode }}-E_{K A}$, and $E_{\text {anode }}$ is the electric potential of the anode $(\mathrm{V})$.

The system formed by Equations (3), (5), (6), and (7) was designed to model the electron transport resistance (CR model). An alternative form of a CR model was also used in the analysis. For a biofilm with high electrical conductivity, the electric current generation kinetics are limited only by biological kinetics, written in terms of the density of electric current according to Equation (8), called the model without resistance to electron transport (SR Model).

$$
\begin{aligned}
j & =F \gamma_{s} f e^{0} q_{\max } \rho_{f} f_{a} L_{f}\left\{\frac{1}{1+\exp \left[-\frac{F}{R T} \eta^{*}\right]}\right\} \\
& =j_{\max }\left\{\frac{1}{1+\exp \left[-\frac{F}{R T} \eta^{*}\right]}\right\}
\end{aligned}
$$

in which $\eta^{*}=E_{\text {anode }}-E_{K A}$.

\section{Numerical Solution}

The CR model was made dimensionless by defining the spatial coordinate $\xi \in[0,1]$ as $\xi=z / L_{f}$.

The equations are rearranged in the new coordinate and represented by Equation system (9), (10), (11), and (12), in which $C$ is the parameter defined as the ratio $k_{b i o} / L_{f}$.

$$
\begin{aligned}
& j=-C\left(\frac{d \eta}{d \xi}\right)_{\xi=0} \\
& C \frac{d^{2} \eta}{d \xi^{2}}-j_{\max }\left\{\frac{1}{1+\exp \left[-\frac{F}{R T} \eta\right]}\right\}=0 \\
& \eta_{\xi=0}=V_{\text {anode }} \\
& C \frac{d \eta}{d \xi}=0
\end{aligned}
$$

The solution of the equations was based on the Finite Difference Method (Patankar, 1980), using a mesh with fifty nodes with fixed spacing $(\Delta \xi)$ of $1 / 49$ between each, to represent the biofilm. The solution of the equation system in discrete form was obtained by Newton's method for nonlinear systems (Burden and Faires, 2011).

\section{Estimation of Parameters}

Data from the CV at a scan rate of $0.2 \mathrm{mV} \mathrm{s}^{-1}$ and in the direction of -0.6 to $0.0 \mathrm{~V}$ vs $\mathrm{Ag} / \mathrm{AgCl}$ were used. The CR and SR models only deal with the electrical current generation, i.e., the electron flow direction occurring from the substrate to the electrode; thus, the portion of the cathodic current was normalized to zero for fitting analyses. 
The parameters of the SR model (Equation (8)), $j_{\max }$ and $E_{K A}$, were estimated by fitting the experimental data using the function fit of the curve fitting tool in the software Matlab (MathWorks, 7:13, USA). The CR model had the $E_{K A}$ and $C$ parameters estimated by minimizing the value of the root mean square error (RMSE, Equation (13)) between the electric current density data observed experimentally $\left(j_{\text {exp }}\right)$ and the data calculated by the model $\left(j_{c a l}\right)$ using an exhaustive calculation routine. The algorithm designed to optimize process parameters was implemented in the software Matlab (MathWorks, $7: 13$, USA). The value of the parameter $j_{\max }$ used in the calculation was the same determined by the SR model fitting.

$$
R M S E=\sqrt{\frac{1}{N} \sum_{n=1}^{N}\left[j_{\exp }(n)-j_{c a l}(n)\right]^{2}}
$$

in which $n$ is the counter of the experimental data and $N$ is the total number of experimental data points.

The performance of the models was evaluated according to two statistical indices: the Root Mean Squared Error (RMSE, Equation (13)) and the coefficient of determination $\left(\mathrm{R}^{2}\right.$, Equation (14)).

$$
R^{2}=1-\frac{\sum_{n=1}^{N}\left[j_{\exp }(n)-j_{c a l}(n)\right]^{2}}{\sum_{n=1}^{N}\left[j_{\exp }(n)-\frac{1}{N} \sum_{n=1}^{N} j_{c a l}(n)\right]^{2}}
$$

\section{RESULTS AND DISCUSSION}

\section{Extracellular Electron Transfer Mechanism}

Figure 2 (A) shows $j v s t$ for 280 days of reactor operation, showing the days in which the operations were performed on a continuous regime. Figures 2 (B) and 2 (C) show $j v s$. $t$ for the first 6 days of the experiment and during the seventh operation on a continuous basis $\left(9.66 \mathrm{~L} \mathrm{~d}^{-1}\right)$, respectively. After the first two days of operation under batch regime, sequential batch operation was started and an increase in electricity generation was observed (Figure 2 (A)) reaching a $j$ value close to the maximum values observed before the fourth day of operation (between 0.30 and $0.35 \mathrm{~A} \mathrm{~m}^{-2}$ ). The electric current density remained stable over the subsequent days of operation. The maintenance of the electrical current generation in an asymptotic value characterizes the saturation phase of the biomass on the anode (Marsili et al., 2008b).
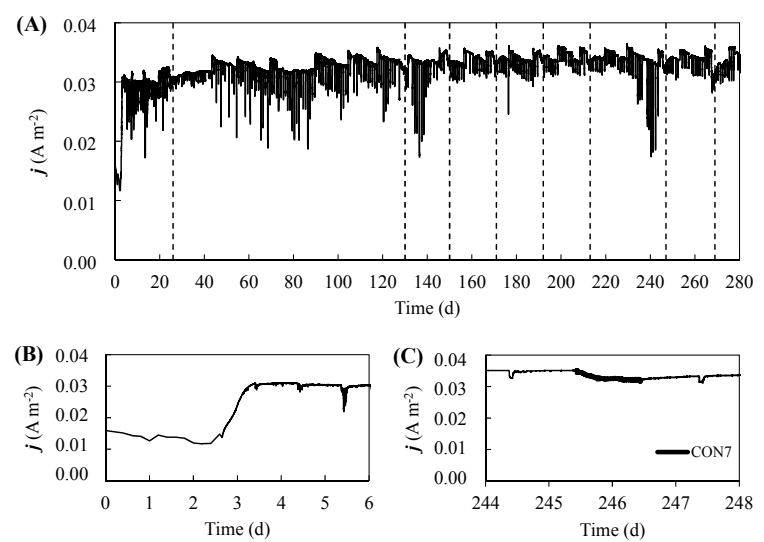

Figure 2: MFC operational results: (A) Time evolution of the electric current density (solid line) and indication of operations in a continuous regime (dotted lines); (B) Density of electric current generated by the MFC in the first 6 days of operation; (C) Density of electric current during the seventh process of operation in the continuous regime $\left(9.66 \mathrm{~L} \mathrm{~d}^{-1}\right)$.

During operations in the continuous regime, the electrical current generation is reduced slightly (in detail of Figure $2(\mathrm{C})$ ), always with reductions below $10 \%$, except for the operation with the flow of 17.77 $\mathrm{L} \mathrm{d}^{-1}$, when the reduction was approximately $16 \%$. This greater drop for the feed flow of $17.77 \mathrm{~L} \mathrm{~d}^{-1}$ may have been the effect of the detachment of cells that make up the biofilm, a result of increased shear force between fluid and biofilm. Marsili et al. (2008a) and Jain et al. (2012) observed reductions of $80 \%$ and $60 \%$, respectively, and also delays in the regeneration of current, resulting from the replacement of the culture medium of electrochemical cells inoculated with different Shewanella species. These microorganisms use mediators as the main mechanism of extracellular electron transport.

Bond and Lovley (2003) observed that the replacement of the medium did not affect the generation of electrical current of a MFC inoculated with $G$. sulfurreducens. Upon replacement of the culture medium, the current was rapidly restored, indicating no influence of bacteria in the suspension or material solubilized in the medium, a behavior similar to that observed in this study. In daily renewals of the MFC's culture medium, abrupt and substantial decreases were observed in current generation (Figure 
2); however, this was quickly reestablished. These declines may be the result of exposure of the anode electrodes to air during the renewal procedures of the medium. In the presence of air, biomass can divert the flow of electrons from the electrode to $\mathrm{O}_{2}$ seeking to increase the rate of energy obtention in the form of ATP (Heijnen, 1999). Moreover, the lack of contact with the culture medium can deplete the available substrate within the biofilm. Sharma et al. (2014) suggest some guidelines related to the robustness of the microbial population in the biofilm, such as: it sustains a certain level of current density for an extended period, the current level can be recuperated by replenishing the substrate or after a metabolic stress (e.g., different substrate concentration or operation mode of the reactor), the biofilm preserves the electrochemical mechanisms, among others.

The CV analyses performed with the reactor effluent are presented in Figure 3 (A) and (B) and corroborate the hypothesis of the use of a predominantly direct EET mechanism. No peaks of anodic or cathodic current, characteristic of the presence of compounds capable of redox reaction (Bard and Faulkner, 2001), such as mediators (Marsili et al., 2008a), were observed at any scan rate (Figure 3 (A)), between 0.2 and $10 \mathrm{mV} \mathrm{s}^{-1}$, or at different time intervals since the beginning of the continuous operation regime (Figure $3(\mathrm{~B})$ ). These results are similar to those presented by Torres et al. (2008) in the study on the establishment of G. sulfurreducens biofilm on the electrode, in which the authors noted the absence of electroactive compounds suspended in the fuel cell based on the results of the CV analysis.

Figure 3 (C) shows the results of the CV analyses performed on the MFC. One can observe differences in the $j$ amplitude in the cycles obtained at different scan rates $\left(0.2,1,2.5,5\right.$, and $\left.10 \mathrm{mV} \mathrm{s}^{-1}\right)$, indicating slow process dynamics characteristic of microbial biofilms, as described by Harnisch and Freguia (2012). For scanning at $0.2 \mathrm{mV} \mathrm{s}^{-1}$, the conditions were within a time range sufficient to sustain microbial catalysis revealed by the sigmoidal profile of current generation versus the electric potential. Sigmoid-shaped voltammetry cycles were observed for all CV analyses. They are characteristic of microbial biofilms using direct EET mechanisms, such as biofilms of G. sulfurreducens or biofilms with domination of $G$. sulfurreducens resulting from its competitive advantage, as observed by many in the literature (Marsili et al., 2008b, 2010; Torres et al., 2008; Srikanth et al., 2008, Richter et al., 2009; Sharma et al., 2014). From Figure 3 is evident that the biofilm attached to the electrode plays a major role in electricity generation, increasing the $j$ amplitude, for example, by two orders of magnitude at a scan rate of $1 \mathrm{mV} \mathrm{s}^{-1}$.

The sigmoid-shaped $\mathrm{CV}$ revealed at the scan rate of $0.2 \mathrm{mV} \mathrm{s}^{-1}$ showed anodic current generation only for values of the electric potential over the region close to $-0.5 \mathrm{~V}$. The positive current reflects acetate oxidation and electron transfer to the electrode. For lower electric potential values $(>-0.5 \mathrm{~V})$, the presence of cathodic current is observed. Srikanth et al. (2008) and Richter et al. (2009) also observed this phenomenon and believe it to be the result of the reduction reaction of some components present in the medium, catalyzed by microorganisms which comprise the biofilm (Gregory et al., 2004). Above $-0.5 \mathrm{~V}$, the current rises continuously until reaching a plateau around $-0.3 \mathrm{~V}$.
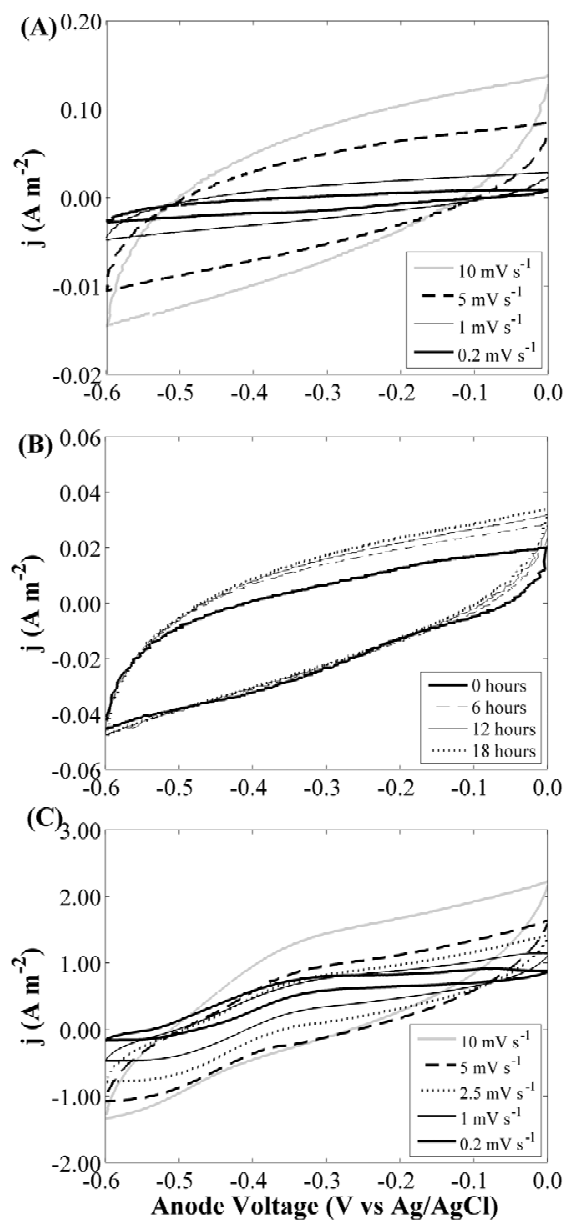

Figure 3: Cyclic voltammetry analyses for: (A) MFC effluent with scan rate at $0.2,1,5$, and $10 \mathrm{mV} \mathrm{s}^{-1}$; (B) MFC effluent with scan rate at $1 \mathrm{mV} \mathrm{s}^{-1}$ for samples collected at $0,6,12$ and 18 hours after starting the continuous regime; (C) MFC with scan rate at $0.2,1$, $2.5,5$, and $10 \mathrm{mV} \mathrm{s}^{-1}$. 
As a main role in an MFC, the external resistance regulates anode availability as an electron acceptor and affects the biofilm diversity. In fact, exoelectrogenic microorganisms compete for substrate with other functional groups (such as fermenters, acetogens, and methanogens) and the external resistance has a strong effect on inhibition and competition among different microorganisms. As reported in previous studies, exoelectrogenic bacteria have preferential development under lower external load systems. However, for practical purposes and in largescale applications, mixed cultures are preferred over pure cultures. Exoelectrogenic biofilms formed by mixed cultures are more tolerant to environmental changes and more accommodating to variable organic matter (González del Campo et al., 2014).

Jung and Regan (2011) studied the effect of $R_{\text {ext }}$ on biofilm communities in an MFC inoculated with anaerobic sludge from a wastewater treatment plant. The authors observed that, at high $R_{\text {ext }}(9.8 \mathrm{k} \Omega)$, the anode bacterial communities were significantly changed, while operating at $0.97 \mathrm{k} \Omega$ and $0.15 \mathrm{k} \Omega$ had no significant effects. In addition, they demonstrated that electrogenesis and methanogenesis were affected by $R_{\text {ext }}$. Rismani-Yazdi et al. (2011), also while studying the effect of $R_{\text {ext }}$ on biofilm communities, observed that the biofilm from an MFC with lower external loads, $0.020 \mathrm{k} \Omega$ and $0.249 \mathrm{k} \Omega$, had $75 \%$ more similarity than those with higher external loads, $0.48 \mathrm{k} \Omega$ and $1 \mathrm{k} \Omega(65 \%$ similarity). In the present study, considering the high external resistance $(1 \mathrm{k} \Omega)$, a mixed biofilm could be expected.

The hypothesis of a predominantly direct mechanism of electron transfer was confirmed by the analysis with scanning electron microscopy shown in Figure 4. Figure 4 (A) shows the surface of a graphite plate similar to the one used as electrode. In Figure 4 (B), there was a dense cluster of cells on the electrode surface and, in the detail in Figure 4 (C), the presence of the cell-like pili (nanowires) extending between bacteria and electrode structures. The cell morphology observed in this figure is similar to that observed by other researchers for exoelectrogenic biofilms (Richter et al., 2008; Pham et al., 2008; ElNagar et al., 2010).

\section{Estimation of Kinetic Parameters}

Figure 5 illustrates the fit of the SR model with the set of experimental data of CV analysis for day 161 of the experiment. Similar results were obtained on the remaining days of analysis. In the region where the increase in the value of the electric current occurs, bounded by the dotted lines, the calculated and the experimental values exhibit a behavior with moderate divergence. Between -0.5 and $-0.3 \mathrm{~V}$, the capacity of cells to generate electrons is in excess, but cells are limited by the availability of an extracellular electron acceptor to transport it to the electrode. Therefore, in this potential range, the anodic current is limited by the electrical resistance imposed by the EET mechanism (LaBelle and Bond, 2010). As can be seen in Figure 6, the CR model showed a better description of the experimental data when compared to the SR model. The CR model fitting obtained an $\mathrm{R}^{2}$ coefficient higher than 0.988 and the RMSE was less than 0.048 for all cases. These results indicate that resistance of the EET mechanics affects the current generation and this was appropriately described as the electrical conductivity of the biofilm by the CR model.
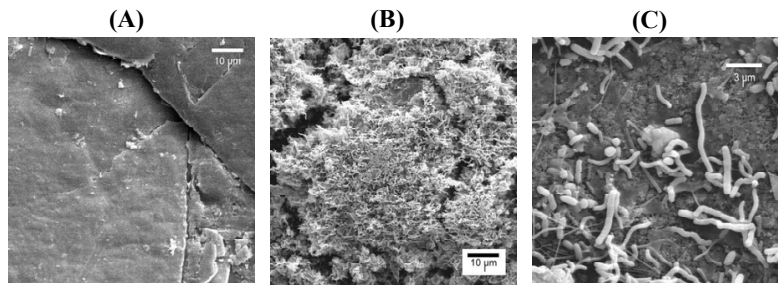

Figure 4: Scanning electron microscopy: (A) Image of the surface of the electrode without biofilm; (B) Image of the electrode surface covered by biofilm and (C) magnification of the electrode surface covered by biofilm.

Anodic current showed an asymptotic behavior at electrical potentials above $-0.3 \mathrm{~V}$ (Figure 6), which results from limiting the intracellular microbial reactions involved in the acetate oxidation process. While the extracellular electron transfer can be accelerated by increasing the electromotive force (increase in electrical potential of the anode), intracellular reactions exhibit a characteristic maximum rate, $q_{\max }$ (LaBelle and Bond, 2010).

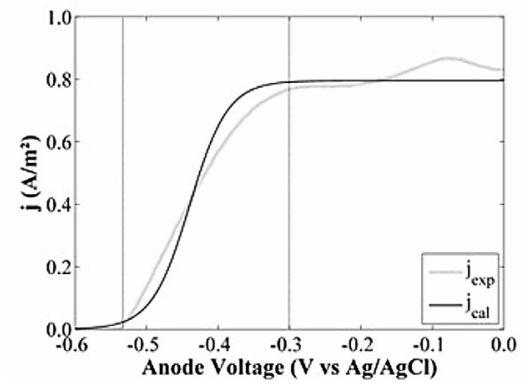

Figure 5: Model without resistance to electron transport (Equation (8) - SR Model) $\left(j_{\text {cal }}\right)$ fitted to the experimental data $\left(j_{\exp }\right)$. 

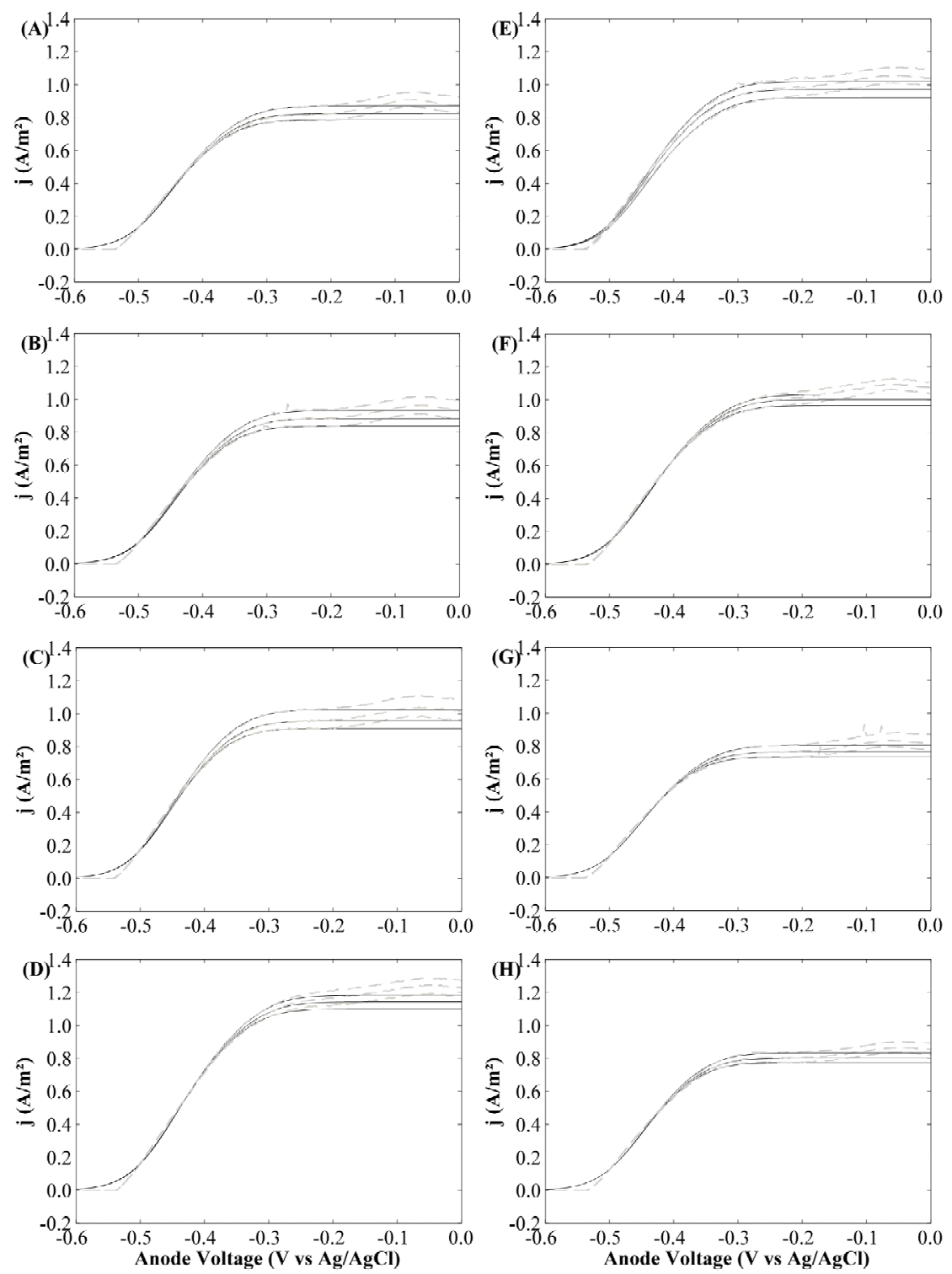

Figure 6: Cyclic voltammetry of the MFC performed at a scan rate of $0.2 \mathrm{mV} \mathrm{s}^{-1}$. Dotted lines represent experimental data and solid lines represent the adjusted CR model. (A) CV on day 161, 10 days after CON3; (B) CV on day 182, 12 days after CON4; (C) CV on day 195, 4 days after CON5; (D) CV on day 206, 15 days after CON5; (E) CV on day 220, 12 days after CON6; (F) CV on day 226, 18 days after CON6; (G) CV performed on day 256, 10 days after CON7; (H) CV on day 275, 7 days after CON8.

The estimated values of characteristic maximum current, $j_{\max }$, showed an average value of $0.954 \mathrm{~A} \mathrm{~m}^{-2}$ and standard deviation equal to $0.118 \mathrm{~A} \mathrm{~m}^{-2}(19.7 \%$ of the average value). The maintenance of the values of this parameter around a mean (low standard deviation) value characterizes the full development of the biofilm on the electrode surface (Marsili et al., 2010; Torres et al., 2008). The $j_{\max }$ parameter values were lower than those obtained for pure cultures of Geo- bacter sulfurreducens and Thermincola ferriacetica fed acetate (order of magnitude of $10^{1} \mathrm{~A} \mathrm{~m}^{-2}$ ) (Torres et al., 2008; Lee et al., 2009; Parameswaran et al., 2013).

The estimated values for $E_{K A}$ (Figure 7 (A)) showed a standard deviation equal to $0.003 \mathrm{~V}$, which corresponds to less than $1 \%$ of the average value of this parameter $(-0.465 \mathrm{~V} v s \mathrm{Ag} / \mathrm{AgCl}$, or $-0.243 \mathrm{~V} v s$ $\mathrm{EPH})$. The value of this parameter was also lower 
than that found for pure cultures of $G$. sulfurreducens fed acetate, $-0.372 \mathrm{~V}$ vs $\mathrm{Ag} / \mathrm{AgCl}(0.15 \mathrm{~V}$ vs $\mathrm{EPH})$ (Marsili et al., 2008b, 2010; Torres et al., 2008; Srikanth et al., 2008) and T. ferriacetica fed acetate, -0.369 vs Ag/AgCl (Parameswaran et al., 2013). The microorganisms that have the lowest values of $E_{K A}$ may be favored in MFC in competition with other cultures that have similar or higher electron transfer speeds, but require a higher-potential electron acceptor (Bond, 2010).

The estimated values for the $C\left(k_{\text {bio }} / L_{f}\right)$ parameter are shown in Figure 7 (B). Their values remained close to the average value of $4.746 \mathrm{~S} \mathrm{~m}^{-2}$ for all analyses (standard deviation $<9 \%$ ). According to Torres et al. (2010), electric conductivity is a physical characteristic inherent to the composition of the biofilm; thus, the value of $C$ would change if the biofilm's thickness or composition varied between the measurements.
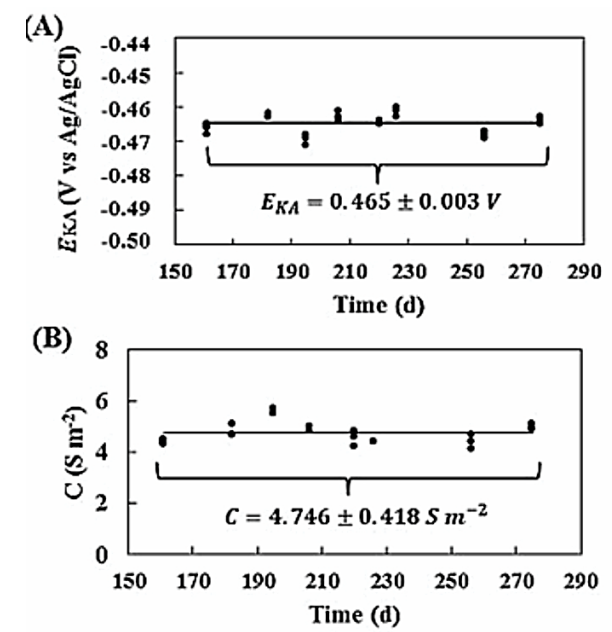

Figure 7: (A) Values of $E_{K A}$ obtained by fitting the $\mathrm{CR}$ model to the $\mathrm{CV}$ experimental data for each cycle of eight analyses. (B) Values of the $C$ parameter estimated by fitting the CR model to experimental data from $\mathrm{CV}$ for each cycle of the eight analyses.

Figure 8 compares the possible values of the parameters $L_{f}$ and $k_{b i o}$ found in this study to those available in the literature (Table 1). The values reported for biofilm thickness are in a narrow range between 10 and $79 \mu \mathrm{m}$. However, for the parameter $k_{\text {bio }}$, values of higher amplitude are shown, with order of magnitude between $10^{-3}$ and $10^{0} \mathrm{mS} \mathrm{cm}^{-1}$. The shaded region in the graph highlights these intervals. Considering that the biofilm thickness in this study does not transcend the values reported in the literature (order of magnitude of $10^{1} \mu \mathrm{m}$ ), it was estimated that the biofilm conductivity value into the MFC under evaluation has the order of magnitude of $10^{-3} \mathrm{mS} \mathrm{cm}^{-1}$. This value is close to that estimated by Sedaqatvand et al. (2013) $\left(k_{\text {bio }}=8.7610^{-4} \mathrm{mS} \mathrm{cm}^{-1}\right)$ using an extend version of the Marcus et al. (2007) model for a single-chamber MFC operating in batch mode with daily replacements of wastewater and a mixed microbial community.

Malvankar et al. (2011) stated that strains of $G$. sulfurreducens that produced the highest densities of electric current had biofilms with the highest electrical conductivity, demonstrating a relation between this density and the network of nanowires produced by the bacteria. In the MFC of the present study, the electrical current densities were lower than those obtained for pure cultures of G. sulfurredeucens, which may indicate a smaller amount of nanowires in the biofilm, expressed by the low value of estimated $k_{b i o}$.

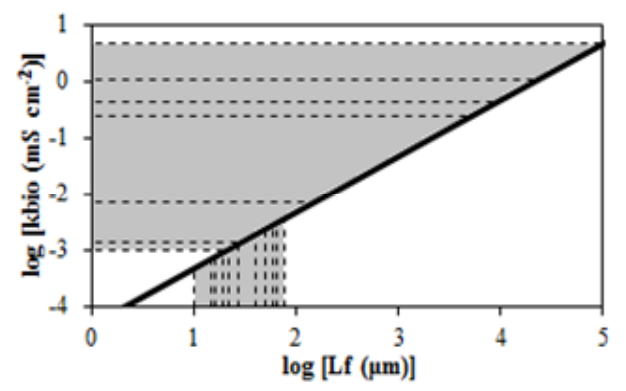

Figure 8: Expected $k_{\text {bio }}$ and $L_{f}$ values obtained by fitting the mathematical model to the experimental data of the MFC (continuous line) compared to the values of these parameters available in the literature (dotted lines). The shaded region comprises the interval of values for each parameter.

Malvankar et al. (2011) stated that strains of $G$. sulfurreducens that produced the highest densities of electric current had biofilms with the highest electrical conductivity, demonstrating a relation between this density and the network of nanowires produced by the bacteria. In the MFC of the present study, the electrical current densities were lower than those obtained for pure cultures of $G$. sulfurredeucens, which may indicate a smaller amount of nanowires in the biofilm, expressed by the low value of estimated $k_{b i o}$.

According to Logan and Regan (2006), MFC biofilms show that there is no single emergent microorganism, but rather a portion of the community can be sustained by alternative metabolisms such as fermentation, methanogenesis, and using an alternative acceptor that does not result in current generation. 
Table 1: Thickness and electrical conductivity of biofilms illustrated in Figure 7 (ED = electron donor; EA = electron acceptor).

\begin{tabular}{|c|c|c|c|c|c|}
\hline Reference & Biomass & ED & EA & $L_{f}(\mu \mathrm{m})$ & $k_{\text {bio }}\left(\mathrm{mS} \mathrm{cm}^{-1}\right)$ \\
\hline Malvankar et al. (2012a) & $\begin{array}{l}\text { G. sulfurreducens strain DL-1 } \\
\text { G. sulfurreducens strain KN400 } \\
\text { G. sulfurreducens strain BEST }\end{array}$ & $\begin{array}{l}\text { acetate } \\
\text { acetate } \\
\text { acetate }\end{array}$ & $\begin{array}{l}\text { gold } \\
\text { gold } \\
\text { gold }\end{array}$ & $\begin{array}{l}50 \\
40 \\
60\end{array}$ & $\begin{array}{l}0.45 \\
4.61 \\
1.09\end{array}$ \\
\hline Malvankar et al. (2012b) & anaerobic biodigester sludge & acetate & gold & 50.3 & 0.25 \\
\hline El-Nagar et al. (2010) & S. oneidensis strain MR-1 & lactate & - & - & $1.0 \times 10^{-3}$ \\
\hline Morita el al. (2011) & cell aggregates ( $25 \%$ Geobacter $)$ & - & - & - & $7.2 \times 10^{-3}$ \\
\hline Summers et al. (2010) & $\begin{array}{l}\text { cell aggregates formed by } G \text {. } \\
\text { sulfurreducens and } G . \\
\text { metallireducens }\end{array}$ & ethanol & fumarate & - & $1.4 \times 10^{-3}$ \\
\hline Marsili et al. (2008b) & G. sulfurreducens PCA & acetate & glassy carbon & 15 & - \\
\hline Torres et al. (2008) & G. sulfurreducens & acetate & graphite & 79 & - \\
\hline Lee et al. (2009) & G. sulfurreducens & acetate & graphite & 66 & - \\
\hline Sppears et al. (2012) & G. sulfurreducens strain PCA & $\begin{array}{c}\text { acetate } \\
\text { methanoate } \\
\text { lactate } \\
\mathrm{H}_{2} \\
\text { acetate+ methanoate } \\
\text { lactate+ acetate }\end{array}$ & $\begin{array}{l}\text { graphite } \\
\text { graphite } \\
\text { graphite } \\
\text { graphite } \\
\text { graphite } \\
\text { graphite }\end{array}$ & $\begin{array}{l}27 \\
22 \\
16 \\
10 \\
27 \\
19\end{array}$ & $\begin{array}{l}- \\
- \\
- \\
- \\
- \\
-\end{array}$ \\
\hline
\end{tabular}

${ }^{\text {a }}$ Bacteria grown with EA (oxygen) limitation. The conductivity value refers only to the nanowire produced by bacteria.

${ }^{\mathrm{b}}$ Cell aggregates obtained in the UASB reactor that converted brewery effluent into methane.

These presences may have led to the difference in the behavior of current generation kinetics of the MFC in this study in relation to the values obtained for pure cultures. In addition, as previously discussed, the metabolisms present in anode biofilms are also influenced by external resistance. An MFC operating at $1 \mathrm{k} \Omega$ and with a microbial consortium has a quite different portion of dominant exoelectrogenic microorganism and behavior compared to a pure culture or an MFC operated with very low resistances, as found by Rismani-Yazdi et al. (2011). In fact, the characteristic kinetic parameters $\left(j_{\max }\right.$, $E_{K A}$, and $\left.k_{b i o}\right)$ are characteristics of both exoelectrogenic biofilm and external resistance.

Malvankar et al. (2011) stated that strains of $G$. sulfurreducens that produced the highest densities of electric current had biofilms with the highest electrical conductivity, demonstrating a relation between this density and the network of nanowires produced by the bacteria. In the MFC of the present study, the electrical current densities were lower than those obtained for pure cultures of $G$. sulfurredeucens, which may indicate a smaller amount of nanowires in the biofilm, expressed by the low value of estimated $k_{b i o}$.

According to Logan and Regan (2006), MFC biofilms show that there is no single emergent microorganism, but rather a portion of the community can be sustained by alternative metabolisms such as fermentation, methanogenesis, and using an alternative ac- ceptor that does not result in current generation. These presences may have led to the difference in the behavior of current generation kinetics of the MFC in this study in relation to the values obtained for pure cultures. In addition, as previously discussed, the metabolisms present in anode biofilms are also influenced by external resistance. An MFC operating at $1 \mathrm{k} \Omega$ and with a microbial consortium has a quite different portion of dominant exoelectrogenic microorganism and behavior compared to a pure culture or an MFC operated with very low resistances, as found by Rismani-Yazdi et al. (2011). In fact, the characteristic kinetic parameters $\left(j_{\max }\right.$, $E_{K A}$, and $k_{b i o}$ ) are characteristics of both exoelectrogenic biofilm and external resistance.

\section{CONCLUSION}

According to the results obtained in this study, it was found that the exoelectrogenic microbiota present in the marine sediment collected on the southern coast of Brazil predominantly uses a direct mechanism of extracellular electron transfer. Multiple evidence points toward EET through a solid conductive matrix including: cyclic voltammetry results, the presence of nanowires observed in scanning electron microscopy images, and the good fit of the mathematical model to experimental data.

The mathematical model properly described the 
electrical current results obtained from the cyclic voltammetry analysis and provided parameter values with physical meaning, which allowed comparing the kinetics parameters of this MFC with other studies. In addition, the model's results indicate that biofilm conductivity plays an important role in the electric current generation in the MFC. The identification of new fonts of exoelectrogenic microorganisms, such as marine sediment collected on the southern coast of Brazil, opens new doors for research involving biological energy generation.

\section{ACKNOWLEDGEMENTS}

The authors gratefully acknowledge financial support and fellowships from CEEE - Companhia Estadual de Energia Elétrica - RS/Brazil, CNPq Conselho Nacional de Desenvolvimento Cientifico e Tecnológico - Brazil, and CAPES - Coordenação de Aperfeiçoamento de Pessoal de Nivel Superior Brazil.

\section{NOMENCLATURE}

\section{Latin Letters}

$A_{\text {Anode }}$ Anode surface area, $\left(\mathrm{m}^{2}\right)$

C Ratio between biofilm conductivity and thickness, $\left(\mathrm{S} \mathrm{m}^{-2}\right)$

$E_{\text {anode }}$ Anode electric potential, (V)

$E_{\text {bio }} \quad$ Biofilm electric potential at a given spatial position, (V)

$E_{K A} \quad$ Biofilm electric potential when

$J_{E D}=0.5 q_{\max } \rho_{f} f_{a} L_{f},(\mathrm{~V})$

$F \quad$ Faraday constant, $\left(\mathrm{C} \mathrm{mol}^{-1}\right)$

$f_{a} \quad$ Volume fraction of active biomass in biofilm, (-)

$f e^{0} \quad$ Coulomb efficiency, (-)

$k_{\text {bio }} \quad$ Biofilm conductivity, $\left(\mathrm{S} \mathrm{m}^{-1}\right)$

$K_{E D} \quad$ Mass concentration of electron donor when $J_{E D}=0.5 q_{\max } \rho_{f} f_{a} L_{f},\left(\mathrm{~g} \mathrm{~m}^{-3}\right)$

$j \quad$ Electrical current density, $\left(\mathrm{A} \mathrm{m}^{-2}\right)$

$j_{\text {cal }} \quad$ Calculated electric current density, $\left(\mathrm{A} \mathrm{m}^{-2}\right)$

$j_{\exp } \quad$ Experimental electric current density, $\left(\mathrm{A} \mathrm{m}^{-2}\right)$

$J_{E D} \quad$ Mass flow of electron donor, $\left(\mathrm{g} \mathrm{m}^{-2} \mathrm{~s}^{-1}\right)$

$j_{\text {max }} \quad$ Specific maximum electrical current density, $\left(\mathrm{A} \mathrm{m}^{-2}\right)$

$L_{f} \quad$ Biofilm thickness, (m) $n \quad$ Counter of the experimental data, (-)

$N \quad$ Total number of experimental data points, $(-)$

$q_{\max } \quad$ Maximum specific rate of electron donor consumption, $\left(\mathrm{g} \mathrm{g}^{-1} \mathrm{~s}^{-1}\right)$

$R_{\text {ext }} \quad$ External resistance, $(\Omega)$

$R \quad$ Universal gas constant, $\left(\mathrm{J} \mathrm{mol}^{-1} \mathrm{~K}^{-1}\right)$

$R^{2} \quad$ Coefficient of determination, (-)

$R M S E$ Root mean square error, $\left(\mathrm{A} \mathrm{m}^{-2}\right)$

$S_{E D} \quad$ Mass concentration of electron donor at a given spatial position of the biofilm, $\left(\mathrm{g} \mathrm{m}^{-3}\right)$

$t \quad$ Time, (s)

$T \quad$ Temperature, $(\mathrm{K})$

$V_{\text {anode }} E_{\text {anode }}-E_{K A},(\mathrm{~V})$

$V_{\text {cell }} \quad$ Voltage between the anode and cathode, (V)

$z \quad$ Spatial coordinate, $(\mathrm{m})$

\section{Greek Letters}

$\begin{array}{ll}\rho_{f} & \text { Specific biofilm mass, }\left(\mathrm{g} \mathrm{m}^{-3}\right) \\ \eta & E_{\text {bio }}-E_{K A},(\mathrm{~V}) \\ \eta * & E_{\text {anode }}-E_{K A},(\mathrm{~V}) \\ \gamma_{s} & \begin{array}{l}\text { Total number of moles of electrons that can } \\ \text { be oxidized per gram of electron donor, } \\ \end{array} \\ & \left(\text { mol g }^{-1}\right) \\ & \text { Dimensionless spatial coordinate }\left(z / L_{f}\right), \\ & (-)\end{array}$

\section{REFERENCES}

Bard, A. J. and Faulkner, L. R., Electrochemical Methods Fundamentals and Applications. John Wiley \& Sons, New York (2001).

Bond, D. R. and Lovley, D. R., Electricity production by Geobacter sulfurreducens attached to electrodes. Applied and Environmental Microbiology, 69, 1548-1555 (2003).

Bond, R. D., Electrodes as Electron Acceptors, and the Bacteria Who Love Them. In: Barton, L. L., Mandl, M. and Loy, A., Geomicrobiology: Molecular and Environmental Perspective. Springer, London, p. 385-400 (2010).

Burden, R. L. and Faires, J. D., Numerical Analysis. 9th Ed., Brooks/Cole, Australia (2011).

ElMekawy, A., Srikanth, S., Bajracharya, S., Hegab, H. M., Nigam, P. S., Singh, A., Venkata Mohan, S., Pant, D., Food and agricultural wastes as substrates for bioelectrochemical system (BES): The synchronized recovery of sustainable energy and 
waste treatment. Food Research International, 73, 213-225 (2015).

El-Nagar, M. Y., Wanger, G., Leung, K. M., Yuzvinsky, T. D., Southam, G., Yang, J., Lau, W. M., Nealson, K. H. and Gorby, Y. A., Electrical transport along bacterial nanowires from Shewanella oneidensis MR-1. Proceedings of the National Academy of Science of the United of States of America, 107, 18127-18131 (2010).

Futamata, H., Bretschger, O., Cheung, A., Kan, J., Owen, R. and Nealson, K. H., Adaptation of soil microbes during establishment of microbial fuel cell consortium fed with lactate. Journal of Bioscience and Bioengineering, 115, 58-63 (2013).

González del Campo, A., Cañizares, P., Lobato, J., Rodrigo, M. and Morales F. J. F., Effects of External Resistance on Microbial Fuel Cell's Performance. In: The Handbook of Environmental Chemistry, Springer (2014).

Gorby, Y. A., Yanina, S., McLean, J. S., Rosso, K. M., Moyles, D., Dohnalkova, A., Beveridge, T. J., Chang, I. S., Kim, B. H., Kim, K. S., Culley, D. E., Reed, S. B., Romine, M. F., Saffarini, D. A., Hill, E. A., Shi, L., Elias, D. A., Kennedy, D. W., Pinchuk, G., Watanabe, K., Ishii, S., Logan, B., Nealson, K. H. and Fredrickson, J. K., Electrically conductive bacterial nanowires produced by Shewanella oneidensis strain MR-1 and other microorganisms. Proceedings of the National Academy of Science of the United of States of America, 103, 11358-11363 (2006).

Gregory, K. B., Bond, D. R. and Lovley, D. R., Graphite electrodes as electron donors for anaerobic respiration. Environmental Microbiology, 6, 596-604 (2004).

Harnisch, F. and Freguia, S., A basic tutorial on cyclic voltammetry for the investigation of electroactive microbial biofilms. Chemistry an Asian Journal, 7, 466-475 (2012).

Heijnen, J. J., Bioenergetics of Microbial Growth. In: Encyclopedia of Bioprocess Technology: Fermentation, Biocatalysis, and Bioseparation. WileyInterscience, New York, p. 267-291 (1999).

Holmes, D. E., Bond, D. R., O’Neil, R. A., Reimers, C. E., Tender, L. R. and Lovley, D. R., Microbial communities associated with electrodes harvesting electricity from a variety of aquatic sediments. Microbial Ecology, 48, 178-190 (2004).

Jain, A., Zhang, X., Pastorella, G., Connolly, J. O., Barry, N., Woolley, R., Krishnamuthy, S. and Marsili, E., Electron transfer mechanism in Shewanella loihica PV-4 biofilms formed at graphite electrode. Bioelectrochemistry, 87, 28-32 (2012).

Jung, S. and Regan, J. M., Influence of external resistance on electrogenesis, methanogenesis and anode prokaryotic communities in microbial fuel cells. Applied and Environmental Microbiology, 77, 564-571 (2011).

Kim, B. H., Park, H. S., Kim, H. J., Kim, G. T., Chang, I. S., Lee, J. and Phung, N. T., Enrichment of microbial community generating electricity using a fuel-cell-type electrochemical cell. Applied Microbiology and Biotechnology, 63, 672-681 (2004).

LaBelle, E. and Bond, D. R., Cyclic Voltammetry for Study of Microbial Electron Transfer at Electrodes. In: Rabaey, K., Angenent, L., Schröder, U., and Keller, J., Bioelectrochemical Systems: From Extracellular Electron Transfer to Biotechnological Application. IWA Publishing, London, p. 137148 (2010).

Lee, H. S., Torres, C. I. and Rittmann, B. E., Effects of substrate diffusion and anode potential on kinetic parameters for anode-respiring bacteria. Environmental Science and Technology, 43, 75717577 (2009).

Logan, B. E. and Regan, J. M., Electricity-producing bacterial communities in microbial fuel cells. Trends in Microbiology, 14, 512-518 (2006).

Lovley, D. L., Electromicrobiology. Annual Review Microbiology, 66, 391-409 (2012).

Malvankar, N. S., Lau, J., Nevin, K. P., Franks, A. E., Touminen, M. T. and Lovley, D. R., Electrical conductivity in a mixed-species biofilm. Applied Environmental and Microbiology, 78, 5967-5971 (2012b).

Malvankar, N. S., Tuominen, M. T. and Lovley D. R., Biofilm conductivity is a decisive variable for high-current-density Geobacter sulfurreducens microbial fuel cells. Energy and Environmental Science, 5, 5790-5797 (2012a).

Malvankar, N. S., Vargas, M., Nevin, K. P., Franks, A. E., Leang, C., Kim, B. C., Inoue, K., Mester, T., Covalla, S. F., Johnson, J. P., Rotello, V. M., Touminen, M. T. and Lovley. D. R., Tunable metallic-like conductivity in microbial nanowire networks. Nature Nanotechnology, 6, 573-579 (2011).

Marcus, A. K., Torres, C. I. and Rittmann, B. E., Conduction-based modeling of the biofilm anode of a microbial fuel cell. Biotechnology and Bioengineering, 98, 1171-1182 (2007).

Marsili, E., Baron, D. B., Shikhare, I. D., Coursolle, D., Gralnick, J. A. and Bond, D. R., Shewanella secretes flavins that mediate extracellular electron transfer. Proceedings of the National Academy of Science of the United of States of America, 105, 3968-3973 (2008a). 
Marsili, E., Rollefson, J. B., Baron, D. B., Hozalski, R. M. and Bond, D. R., Microbial biofilm voltammetry: Direct electrochemical characterization of catalytic electrode-attached biofilms. Applied and Environmental Microbiology, 74, 7329-7337 (2008b).

Marsili, E., Sun, J. and Bond, D. R., Voltammetry and growth physiology of Geobacter sulfurreducens biofilms as a function of growth stage and imposed electrode potential. Electroanalysis, 22, 865-874 (2010).

Morita, M., Malvankar, N. S., Franks, A. E., Summers, Z. M., Giloteaux, L., Rotaru, A. E., Rotaru, C. and Lovley, D. R., Potential for direct interspecies electrons transfer in methanogenic wastewater digester aggregates. MBio, 2 (2011).

Niessen, J., Harnisch, F., Rosenbaum, M., Schröder, U. and Scholz, F., Heat treated soil as convenient and versatile source of bacterial communities for microbial electricity generation. Electrochemistry Communications, 8, 869-873 (2006).

Oliveira, V. B., Simões, M., Melo, L. F. and Pinto, A. M. F. R., An overview on the developments of microbial fuel cells. Biochemical Engineering Journal, 73, 53-64 (2013a).

Oliveira, V. B., Simões, M., Mello, L. F. and Pinto A. M. F. R., 1D mathematical model for a microbial fuel cell. Energy, 61, 463-471 (2013b).

Pant, D., Van Bogaert, G., Diels, L. and Vanbroekhoven, K. A., Review of the substrates used in microbial fuel cells (MFCs) for sustainable energy production. Bioresource Technology, 101, 1533-1543 (2010).

Parameswaran, P., Bry, T., Popat, S. C., Lusk, B. G., Rittmann, B. E. and Torres, C. I., Kinetic, electrochemical, and microscopic characterization of the thermophilic, anode-respiring bacterium Thermincola ferriacetica. Environmental Science and Technology, 47, 4934-4940 (2013).

Patankar, S. V., Numerical Heat Transfer and Fluid Flow. Routledge, New York (1980).

Pham, H. T., Boon, N., Aelterman, P., Clauwaert, P., De Schamphelaire, L., van Oostveldt, P., Verbeken, K., Rabaey, K. and Verstraete, W., High shear enrichment improves the performance of the anodophilic microbial consortium in a microbial fuel cell. Microbial Biotechnology, 1, 487-496 (2008).

Picioreanu, C., Katuri, K. P., van Loosdrecht, M. C. M., Head, I. M. and Scott, K., Modelling microbial fuel cells with suspended cells and added electron transfer mediator. Journal Applied Electrochemical, 40, 151-162, (2010).

Picioreanu, C., Head, I. M., Katuri, K. P., van
Loosdrecht, M. C. M. and Scott, K., A computational model for biofilm-based microbial fuel cells. Water Research, 41, 2921-2940 (2007).

Pinto, R. P., Srinivasan, B., Manuel, M. F. and Tartakovsky, B., A two-population bio-electrochemical model of a microbial fuel cell. Bioresource Technology, 101, 5256-5265 (2010).

Rabaey, K., Boon, N., Siciliano, S. D., Verhaege, M. and Verstraete, W., Biofuel cells select for microbial consortia that self-mediate electron transfer. Applied and Environmental Microbiology, 70, 5373-5382 (2004).

Reguera, G., Nevin, K. P., Nicoll, J. S., Covolla, S. F., Woodard, T. L. and Lovley, D. R., Biofilm and nanowire production leads to increased current in Geobacter sulfurreducens fuel cells. Applied and Environmental Microbiology, 72, 7345-7348 (2006).

Richter, H., Mccarthy K., Nevin, K. P., Johonson, J. P., Rotello, V. M. and Lovley, D. R., Electricity generation by Geobacter sulfurreducens attached to gold electrodes. Lagmuir, 24, 4376-4379 (2008).

Richter, H., Nevin, K. P., Jia, H., Lowy, D. A., Lovley, D. R. and Tender, L. M., Cyclic voltammetry of biofilms of wild type and mutant Geobacter sulfurreducens on fuel cell anodes indicates possible roles of OmcB, OmcZ, type IV pili, and protons in extracellar electron transfer. Energy and Environmental Science, 2, 506-516 (2009).

Rismani-Yazdi, H., Christy, A. D., Carver, S. M., Yu, Z., Dehority, B. A. and Touvinen, O. H., Effect of external resistance on bacterial diversity and metabolism in cellulose-fed microbial fuel cells. Bioresource Technology, 102, 278-283 (2011).

Rittmann, B. E. and McCarty, P. L., Environmental Biotechnology: Principles and Applications. McGraw Hill, New York (2001).

Sedaqatvand, R., Esfahany, M. N., Behzad, T., Mohseni, M. and Mardanpour, M. M., Parameter estimation and characterization of a singlechamber microbial fuel cell for dairy wastewater treatment. Bioresource Technology, 146, 247-253 (2013).

Sharma, M., Bajracharya, S., Gildemyn, S., Patil, S. A., Alvarez-Gallego, Y., Pant, D., Rabaey, K. and Dominguez-Benetton, X., A critical revisit of the key parameters used to describe microbial electrochemical systems. Electrochimica Acta, 140, 191-208 (2014).

Speears, A. and Reguera, G., Electron donors supporting growth and electroactivity of Geobacter sulfurreducens anode biofilms. Applied and Environmental Microbiology, 78, 437-444 (2012).

Srikanth, S., Marsili, E., Flickinger, M. C. and Bond, 
D. R., Electrochemical characterization of Geobacter sulfurreducens cells immobilized on graphite paper electrodes. Biotechnology and Bioengineering, 99, 1065-1073 (2008).

Summers, Z. M., Fogarty, H. E., Leang, C., Franks, A. E., Malvankar, N. S. and Lovley, D. R., Direct exchange of electrons within aggregates of an evolved syntrophic coculture of anaerobic bacteria. Science, 330, 1413-1415 (2010).

Tender, L. M., Reimers, C. E., Stecher III, H. A., Holmes, D. E., Bond, D. R., Lowy, D. A., Piobello, K., Fertig, S. J. and Lovley, D. R., Harnessing microbially generated power on the seafloor. Nature Biotechnology, 20, 821-825 (2002).

Torres, C. I., Marcus, A. K., Lee, H. S., Parameswaran, P., Krajmalnik-Brown, R. and Rittmann, B. E., A kinetic perspective on extracellular electron transfer by anode-respiring bacteria. FEMS Microbiology Reviews, 34, 3-17 (2010).

Torres, C. I., Marcus, A. K., Parameswaran, P. and Rittmann, B. E., Kinetic experiments for evaluating the Nernst-Monod model for anode-respiring bacteria (ARB) in a biofilm anode. Environmental Science and Technology, 42, 6593-6597 (2008).

Venkata Mohan S., Velvizhi, G., Annie Modestra, J., Srikanth, S., Microbial fuel cell: Critical factors regulating bio-catalyzed electrochemical process and recent advancements. Renewable and Sustainable Energy Reviews, 40, 779-797 (2014).

Zeng, Y., Choo, Y. F., Kim, B. H. and Wu, P., Modelling and simulation of two-chamber microbial fuel cell. Journal of Power Sources, 195, 7989 (2010). 